\title{
Midterm 2018 and targeting Latino community through misinformation and disinformation online
}

\author{
Manjul Shrestha \\ West Virginia University, ms0123@mix.wvu.edu
}

Follow this and additional works at: https://researchrepository.wvu.edu/etd

Part of the American Politics Commons

\section{Recommended Citation}

Shrestha, Manjul, "Midterm 2018 and targeting Latino community through misinformation and disinformation online" (2018). Graduate Theses, Dissertations, and Problem Reports. 3704.

https://researchrepository.wvu.edu/etd/3704

This Thesis is protected by copyright and/or related rights. It has been brought to you by the The Research Repository @ WVU with permission from the rights-holder(s). You are free to use this Thesis in any way that is permitted by the copyright and related rights legislation that applies to your use. For other uses you must obtain permission from the rights-holder(s) directly, unless additional rights are indicated by a Creative Commons license in the record and/ or on the work itself. This Thesis has been accepted for inclusion in WVU Graduate Theses, Dissertations, and Problem Reports collection by an authorized administrator of The Research Repository @ WVU. For more information, please contact researchrepository@mail.wvu.edu. 


\title{
Midterm 2018 and targeting Latino community through misinformation and disinformation online
}

\section{Manjul Shrestha}

\author{
Thesis submitted to the \\ Benjamin M. Statler College of Engineering and Mineral \\ Resources at West Virginia University
}

in partial fulfillment of the requirements for the degree of

Master of Science in

Computer Science

Saiph Savage, Ph.D., Chair

Yanfang Ye, Ph.D.

Roy Nutter, Ph.D.

Lane department of Computer Science and Electrical Engineering

Morgantown, West Virginia

2018

Keywords: social media, misinformation, disinformation, midterm, election, multi-platform, election, Latino, politics, minorities

Copyright 2018 Manjul Shrestha 


\section{ABSTRACT}

\section{MIDTERM ELECTION AND MISINFORMATION AND DISINFORMATION TARGETING LATINO}

\section{Manjul Shrestha}

How has the Latino community been targeted by digital propaganda during the 2018 midterm elections in the US? How might this affect their involvement in and around the election? This thesis starts to answer these questions through a data analysis on two of the most prominent and popular social media platforms for political discussion: Twitter and Reddit. This study analyzed people's posting patterns over time, the digital traces of the individuals pushing the majority and most popular content, and Latino candidates' interaction on Twitter. This research provides evidence that on Twitter there are two main actors discussing Latinos and politics: "Pro-Latino NGOs" and "Pro-Trump one hit wonders." The Non-Governmental Organizations (NGOs) discussed political events sporadically and focused more on helping Latinos who had been long term in the US to obtain better work opportunities, as well as registering to vote. The one-hit wonders were famous people who posted one tweet highlighting the positive things US president Trump has done with Latinos and received massive attention from audiences (in terms of retweets and likes). On Reddit, it was identified that there was a mix of highly active people: (1) individuals posting about president Trump being racist against Latinos; (2) people who simply posted news stories about Latinos and politics; and (3) political trolls focused on mobilizing people to vote republican (pro-Trump) in the elections. The political trolls shared stories of how 
Latinos across the US were also supporting Trump and how Trump's policies against illegal immigrants from Latin America was beneficial to the US. These trolls also appeared to coordinate with high profile people to gain mass visibility outside Reddit for their cause.

As the Latino voters, the second largest population group in the US, prepared to head to the polls, humanizing the effects of disinformation against Latinos becomes crucial. Most political actors are not mentioning or organizing Latinos on Twitter. The political organizations, specifically NGOs, that do focus on Latinos rarely discuss politics and focus more on helping Latinos to thrive in the US. Hence, this research is currently highlighting that there is gap between Latinos and the US midterm elections. It appears that it is more the extremist voices, such as political trolls, who are engaging Latinos for months before the election. In the data we analyzed, there currently does not appear to be any group that is actively mobilizing Latinos to vote without falling into extreme behaviors. We finish by discussing recommendations to counterattack and diminish the effects of disinformation targeting the Latino community and increase their involvement in future US election by use of a civic tech by NGOs. 


\section{ACKNOWLEDGEMENTS}

Foremost, I would like to express my sincere gratitude to my advisor Dr. Saiph Savage for the continuous support of this research, for her patience, motivation, enthusiasm, and immense knowledge. Her guidance helped me in all the time of research and writing of this thesis. I could not have imagined having a better advisor and mentor.

Besides my advisor, I would like to thank the rest of my thesis committee: Dr.

Yanfang Ye, Dr. Roy Nutter, for their encouragement, insightful comments, and thoughtful questions.

Furthermore, I wish to acknowledge the Lane Department of Computer Science and Electrical Engineering for giving me the opportunity to pursue my master's degree in such an academically vibrant environment.

Finally, I am grateful to my parents, my family and my close friends. Without their support, and their love, I would not be able to complete this project. 


\section{Content}

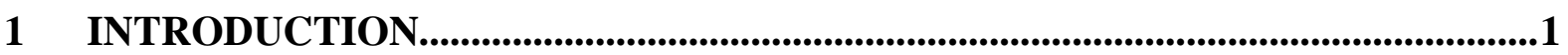

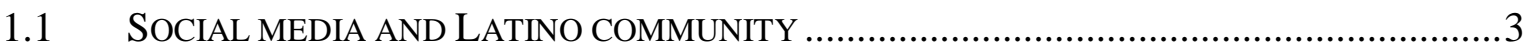

1.2 Disinformation AND MisINFORMATION VIA SOCIAL MEDIA .................................

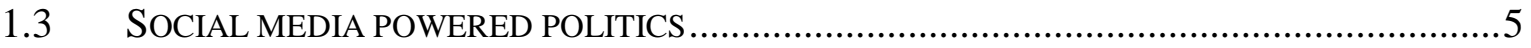

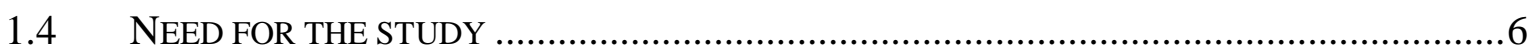

2 LITERATURE REVIEW …......................................................................................

2.1 MISINFORMATION AND DISINFORMATION, AND ITS RELATIONSHIP WITH RECEIVERS ..7

2.2 MOBILIZING LATINO COMMUNITY FOR POLITICAL CAUSE ........................................ 8

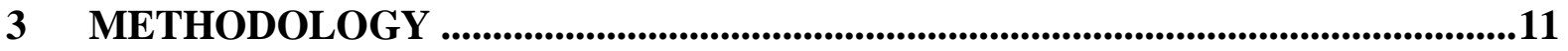

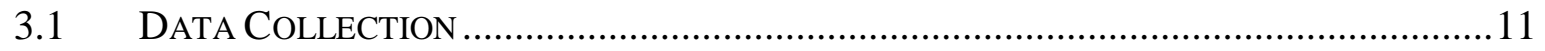

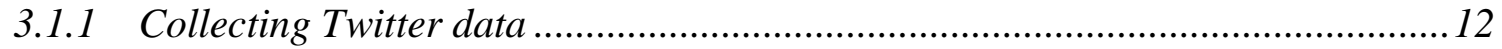

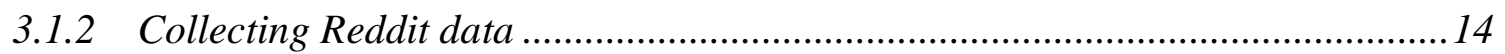

3.2 LEARNING HOW LATINOS WERE TARGETED ...................................................... 15

3.2.1 Targeting Latino crowd through Twitter ......................................................... 16

3.2.2.1 Understanding how the Latino community were targeted overtime on

Twitter 16

3.2.2.2 Understanding who were the people targeting Latino community on Twitter 16

3.2.2.3 Understanding level of emotions shown by people and interaction show by

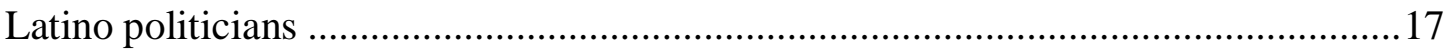

3.2.3 Targeting Latino Crowd through Reddit ............................................................ 18 
3.2.3.1 Understanding how the Latino community were targeted overtime on

Twitter 18

3.2.3.2 Understanding who were the people targeting Latino community on Twitter 19

4 DATA ANALYSIS AND RESULTS .20

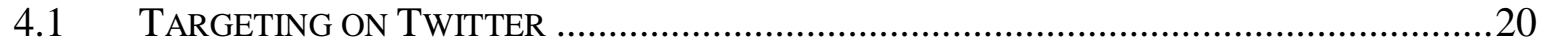

4.1.1 Understanding how Latino communities were targeted overtime ......................20

4.1.2 Understanding who were the people targeting Latinos .....................................22

4.1.3 Understanding level of emotions shown by people and interaction shown by

Latino politicians .25

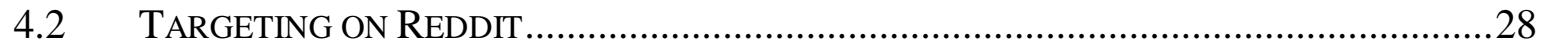

4.2.1 Understanding how Latino communities were targeted overtime ......................28

4.2.2 Understanding who were the people targeting Latinos .....................................30

4.3 COMPARING THE TARGET DIRECTED TOWARDS LATINO COMMUNITY ON TWITTER

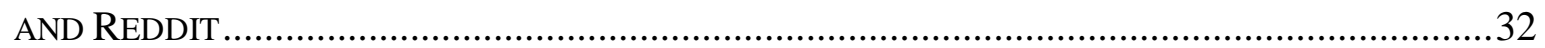

5 DESIGNING CIVIC TECH TO TARGET AND MOBILIZE LATINOS................34

5.1 BOT TO MOBILIZE LATINO CROWD TO ENGAGE IN POLITICS ...................................35

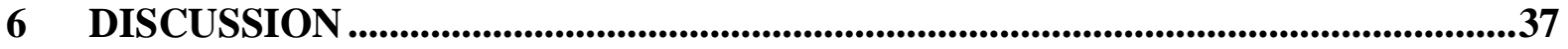

7 CONCLUSION, LIMITATION AND FUTURE WORKS........................................40 


\section{List of Figures}

2.2 Latino Political behavior respect to shared ethnicity................9

3.1.1 (a) Workflow of collecting data from Twitter.....................12

3.1.1 (b) A snapshot of Twitter data collected after cleaning the data......13

3.1.2 A snapshot of Reddit data collected after cleaning the data...........14

4.1.1 Overview of peoples posting behavior for content related to Latino and midterm in Twitter.

4.1.2 Overview of how much each individual posted on Twitter and the interaction they received from other users...........................23

4.1.3 (a) Overview of user's average number of emotional words used on

Twitter....

4.1.3 (b) The number of tweets where Latino politicians interacted vs number of tweets dedicated for broadcast.

4.2.1 Overview of peoples posting behavior for content related to Latino and midterm in Reddit. .28

4.2.2 Overview of how much each individual posted on Reddit and the interaction they received from other users.

5.1 Workflow of how NGO can use bot to share information .35

5.2 A python script to run twitter bot and share information 36 


\section{List of Table}

3.1.1 Total post collected after cleaning data for both the social media account.

3.1.2 Number of tweets collected for political candidates under

study .15 


\section{Chapter 1}

\section{Introduction}

As social media sites like Facebook, Twitter and YouTube are being used by every two out of three people in the United States [1] and search engines being used daily [2], it is a high time to monitor what people have been sharing online and/or searching online in order to know what they currently care about. This sharing of information online can be targeted towards the public in order to manipulate their thoughts without knowing about it. This is especially true during elections where minority groups can be targeted on social media to earn their votes [47]. In the 2008 and 2012 U.S. presidential campaigns, there was a belief that digital tools could enhance democracy by expanding citizen empowerment and engagement [4]. However, after the 2016 US presidential campaign new concerns arose highlighting that social media may have been weaponized to undermine democracy [5]. Current research has been investigating how social media was used as a tool to share computational propaganda for spreading disinformation or causing social disruptions [6,7]. Political candidates are involved in social media strategy so as to influence both individuals' lives and society as a whole [3].

According to the Pew Research Center, 27.3 million Latinos were eligible to vote in 2016. This number is greater than any other racial or ethnic group of voters, representing $12 \%$ of all eligible voters [8]. For the midterm election 2018, the number of eligible Latino voters has gone up to 29 million but the Latino voter turnout for midterm election has declined since 
2006 [9]. Therefore, understanding how Latinos are being targeted through social media during elections is a vital study to ensure the fair election in the United States.

This thesis paper is trying to answer the question of how Latinos are being targeted on social media during the political election. The study is also trying to understand how misinformation or disinformation might be shared online targeting or involving Latinos. The paper will try to analysis and answer these research question keeping in mind the 2018 midterm election and using the post, from September 24, 2017, to September 24, 2018, for two of the most popular social media platforms for social media discussion: Twitter and Reddit. This thesis will try to illustrate the content that people post about the Latino community and midterm election 2018 using analytical techniques similar to those for examining disclosure between politicians and their audiences [10]. It also aim to explore the contents on these social media platforms under post related to Latino and midterm election gain attention over time and investigate the behavioral pattern who are pushing such content over time.

From the analysis, the study uncovered that on Twitter, there is a strong presence of political NGO's targeting Latinos. However, most of these political NGOs' primary focus was on improving work opportunities of Latinos and their rights regarding immigration than to share information regarding the election. These posts shared by NGO's on twitter were addressed towards Latino community who have been staying in the United States for a long time or have earned their way towards citizenship. The post regarding midterm was shared to the minimal by these NGOs' and was shared during the verge of the election and was focused much on requesting the Latinos to register to vote but no information regarding voter's right. While on Reddit, this study could identify conversations on different subreddits which came 
from extreme voices, such as pro-Trump political trolls. These voices had numerous strategies for engaging people in topics about Latinos and election, which ranged from posts that would allow people to directly talk with different politicians through AMAs to MEGAthread posts where people had deep conversations regarding political topics that the people cared about. Furthermore, on analyzing of Twitter posts of the Latino political candidates for the midterm election 2018, Latino political candidates show much more interest in interacting with accounts of other users than just broadcasting tweets.

\subsection{Social media and Latino community}

Wikipedia defines Latino as people who are living in the United States who are descendants of people from countries of Latin America and the Iberian Peninsula. The United States has the highest number of people who identify themselves as Latino outside of Latin America with full or partial lineage to Latinos $[13,14]$. This group of minorities has been very successful when it comes to using social media to engage themselves through social media.

Latinos tend to use more social media compared to non-Latino in the US and tend to share the contents they see online five times more than Non-Latino [32]. With Latinos' increasing use of digital phones, social media are always on their fingertips. With 1 in every 4 Latino using Twitter, which is above the national average, a study found out that Latinos were more likely to take an issue online on social media before taking any decision and are active on social sites and are longing for cultural identification and personal connection [33]. These active group of social media enthusiasts are also known to use social networking as a means for strengthening their economic as well as political presence on the Internet. 


\subsection{Disinformation and Misinformation via Social Media}

Disinformation can be defined as intentionally sharing of information which is false so as to deceive people receiving the information [18]. Whereas, misinformation can be defined as sharing of information which is false without actually the informer actually knowing if the information is true or false [19]. Some people believe the reason Trump won the presidential election is due to the influence of misinformation and disinformation [11]. With the rise of users in social media, the people sharing this disinformation and misinformation seems to be very high. And with ease of data availability, it is difficult to rely on the information shared via the social media platform and creates confusion [24]. The way global warming was defined as a fraud to diminish liberty and weaken democracy by a blogger explains a lot about misinformation out on the market [25]. A popular example of disinformation was "Obama being a foreign-born US citizen."

Facebook and Twitter are fighting against these kinds of information. Facebook is trying to crowdsource media credibility, but this method has found to be extremely difficult and unreliable [20]. Part of the reason is people are easily fooled by fake news and it is hard to find a reliable source of information. Misinformation might not only be defined in terms of information. Recently, the number of followers for an account or how popular a post shared by an account has been linked to a candidate's popularity for election. With thousands of bot lurking in the Twitter universe, it is difficult to measure the popularity based on these parameters anymore. These bots have the power to follow users, like their posts or retweet the post as much as they want. Twitter has tried its best to detect them by purging many such accounts [22]. This saw many influential people on social media platform to lose lots of their followers [21]. 
Reddit is an American social news aggregation, news content rating and discussion website. This has also seen its own share of misinformation. But it has a famous new way to share misinformation: trolls, and memes. The way a subreddit, The_Donald, organized the "Great Meme War" to harass Trump's opponents and flood the Internet with pro-Trump, anti-Hillary Clinton memes speak on its own [10].

\subsection{Social media powered politics}

With the midterm election in the United States being held in November of every four years, near to the halfway of United States President's four-year term of province, it is estimated that only 40 percent of people eligible to vote show up for midterm election whereas 50 to 60 percent for the presidential election $[15,16]$. Facebook published a reported after the midterm 2010 election stating that $74 \%$ of House candidates and $84 \%$ of Senatorial candidates with and Facebook fans won the election [34]. Traditionally, engagement in politics would be considered as volunteering or voting, but with the advance and involvement of different social media, it is difficult to draw a line of what political engagement could look like. Is talking about a politician online or sharing a political view online in a virtual space same as sharing that information in a physical space and is that a political engagement? The Latino voter showing up for midterm election has been in decline since 2006 [9] and hit lowest during the 2014 midterms. However, Latino interest for the midterm election 2018 has been higher by 14 percent when compared to 2014 midterm election [17]. Social media seems to have provided the minority group with their own channels for political engagement. Twitter, in particular, acts as a platform where minority group discuss (African Americans and Latino American), debate and form political campaign and strategies [36]. If minority group tend to feel left out from the traditional engagement channels, they take it to the social 
media to engage in political discussions. It was found that digital political engagement is the one that triggered people to engage in traditional political activities. [36].

\subsection{Need for the study}

As the second largest minority group, who love to use social media, made its way to election booths for the midterm election [9], the study regarding how social media has targeted Latinos during elections becomes a crucial study. While many studies have been done on how people are being targeted by sharing different information online on social media, we lack knowledge on how it is being utilized to target the minority group, especially Latinos [11]. The extreme voices that might be hidden in social media platforms who are targeting Latino community and sharing different information regarding the midterm election need to be exposed. Also, the extent to which this was happening as the election was looming needs to be exposed. 


\section{Chapter 2}

\section{Literature Review}

There have been few existing studies done about misinformation shared online and about mobilizing Latino crowd. There are two areas of prior literature to look into: (1) Misinformation and disinformation, and its relations ship with receivers and (2) Mobilizing Latino community for the political cause. This background study helped us identify a gap in our understanding of how misinformation online has been mobilizing Latino crowd during elections. Keeping the current government's policies in mind, the Latino crowd could be easily targeted by individuals, groups or organization towards receiving misinformation regarding an election.

\subsection{Misinformation and disinformation, and its relationship with receivers}

Peter has raised a discussion about misinformation and disinformation through internet [23]. He mentions that navigating huge amounts of data on the internet to find the most relevant and high quality is a very big challenge. He discusses that text, images or even the whole news are subject to manipulation and alteration and could be passed around as genuine. From his experiment, which interviewed people regarding disinformation created for the experiment purpose, he argued that marking each article present on the internet as true is difficult. Also, he mentions that if people are not knowledgeable about certain topics then it is easy for the misinformation or disinformation to appear genuine. This can be misused when it 
comes to politics as many people, especially minority groups, are not much aware of political laws or they are scared of it.

[31] tires to show some insights about cascade dynamics on social media relative to misinformation. The paper tries to study how different category of news: scientific, conspiracy and trolling news live their lives on the internet. The study found out scientific news tends to distribute quickly but the interest on such news decreases with time. But rumors tend to distribute more slowly but tend to gain interest as their time online increases. Also, the study suggested that users tend to accumulate in communities for any popular news (genuine or fake), which causes more reinforcement and promotes confirmation bias, segregation, and polarization.

Brian studies how anger and anxiety play a vital role of whether citizens consider misinformation in a partisan or open-minded fashion [26]. They found out emotions play an important role when people are exposed to political misinformation. Anger causes people to believe misinformation that are consistent with the receivers supported political party. Whereas anxiety encourages beliefs based on information environment than partisanship.

\subsection{Mobilizing Latino community for political cause}

In paper [35], the authors have tried to understand if Latino community can be influenced to take part in political elections if there is a presence of Latino candidates running during an election and sharing information with the community. Authors argue about two things, firstly ethnic candidates increase the level of interest in election to co-ethnic voters and secondly, ethnic candidates direct more resources to mobilize the co-ethnic community. Figure 2.2 shows how the presence of a Latino candidate affects Latino voter turnout. 


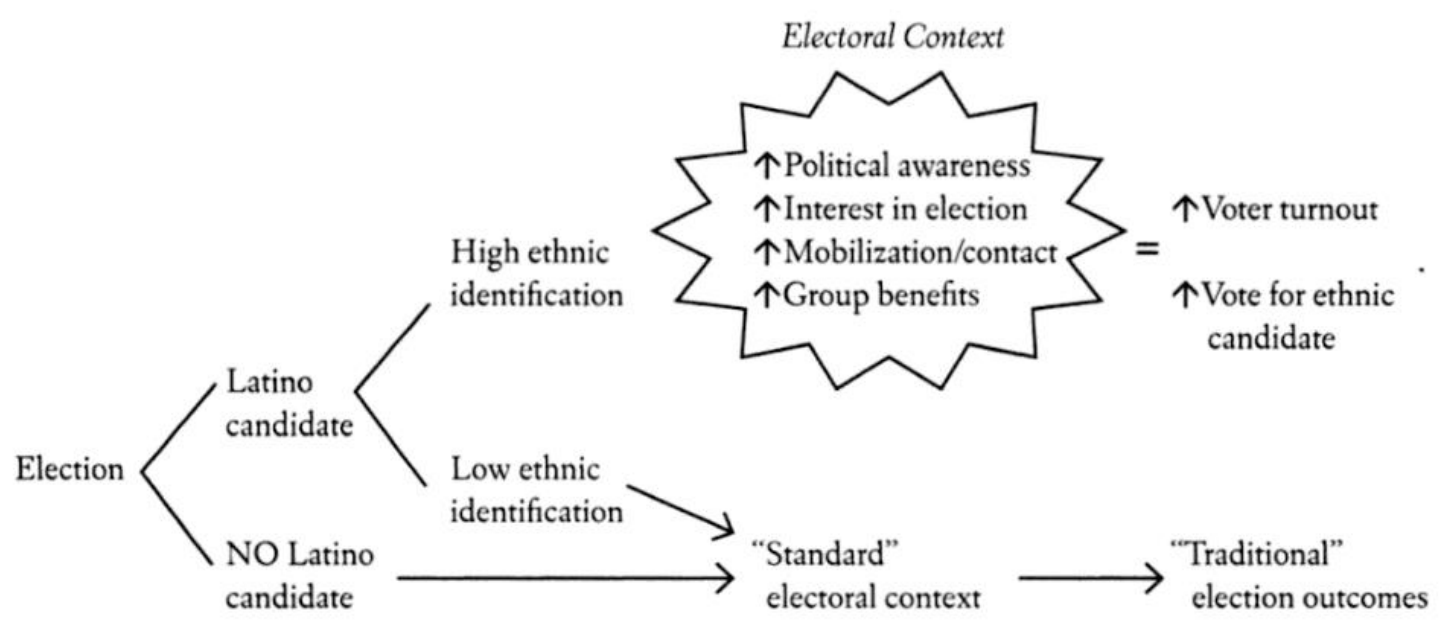

Figure 2.2 Latino Political behavior respect to shared ethnicity

[27] illustrates that it is easy to mobilize individuals like Catholics, Spanish speakers, foreign-born individuals, and Mexican origin when predicting how are individuals, family and friend are mobilized. But looking at the individual level of participation, the study found out, second-generation and third-generation Latinos were more likely to participate in marches as to foreign-born Latinos. Also, the study found out that, Latinos from different states are equally active when it comes to political agenda regardless of the size of the Latino community in that state. The study also found that people who are ready to be mobilized are the one who had serious concerns regarding immigration or who supported a pathway for citizenship for undocumented.

Some of the studies tried to understand how it can be easy to mobilize Latino voters. Melissa did a studied on how to increase Latino voters during elections [28]. She argues that Latino voters can be increased through personal outreach from a candidate personally reaching out to them. She says this can significantly be higher if the candidate approaching is a Latino politician. Whereas, [29] found out that Spanish language radio, which Latino could relate as 
more personal to them, was more effective than remainders sent by email, leaflets, or phone calls. Based on the paper [30], human behavior is a result of three factors: motivation, ability, and trigger. And given there is high motivation and ability, people usually need a trigger to bring that change in the behavior which the author here has called signal trigger. A star amazon book review for Megan Kelly’s book [39] and boycotting Netflix shows that oppose anti-Trump political views [38] are few examples for mobilizing crowd through a small thing like a Reddit thread [10].

[41] studied the case of "El Bronco". They did a study on a politician's use of social media to communicate with the public. It was clear that this was a primary reason and one of the first where a candidate won, and his page became a key engagement tool for policy conversation among citizens way beyond the election day. They found out that, if the political candidate and public are on same social media, then it would be easy for the political candidate to increase civic engagement of people through that platform. 


\section{Chapter 3}

\section{Methodology}

This thesis was indented to understand the following question: How Latinos are being targeted during the midterm election by digital propaganda? Here, "targeting Latino" means discussing or mentioning Latino or any slangs related to the term on the post of the two social media. To answer the question, posts from Sep 24, 2017, to Sep 14, 2018, was studied from two of the most prominent social media platforms for political discussion: Twitter and Reddit.

\subsection{Data Collection}

Data were collected using Twitter streaming API and Reddit streaming API, which collects post across different subreddits. All the data collected were publicly available for anyone to view unless the privacy setting of the user was modified in which case, it would not be able to retrieve the posts. The details of the dataset are shown in Table 3.1.

To identify the Twitter and Reddit content related to Latinos and the midterm elections a manual list of keywords was created, related to the Latino Community and the midterm elections. The primary lists of keywords were "DACA", "Census 2020”, "Midterms"," build wall", "election". Synonyms were included for words that were used for "Latino" in order to collect posts and tweets from different social groups referencing them (e.g., "Hispanic" is a very slang for Latinos, some people call Latinos "Beeners" to reference them in a derogatory form; Latinos from California sometimes call themselves "Chicanos"). To identify keywords 
related to the midterm elections, news reports and the midterm election were used. Wikipedia was used pages to identify all proper names (i.e., list of candidates, and the related people involved) and major group organization participating in the election. To avoid biasness on the information collected, these news sites were used to involve all political views.

\subsubsection{Collecting Twitter data}

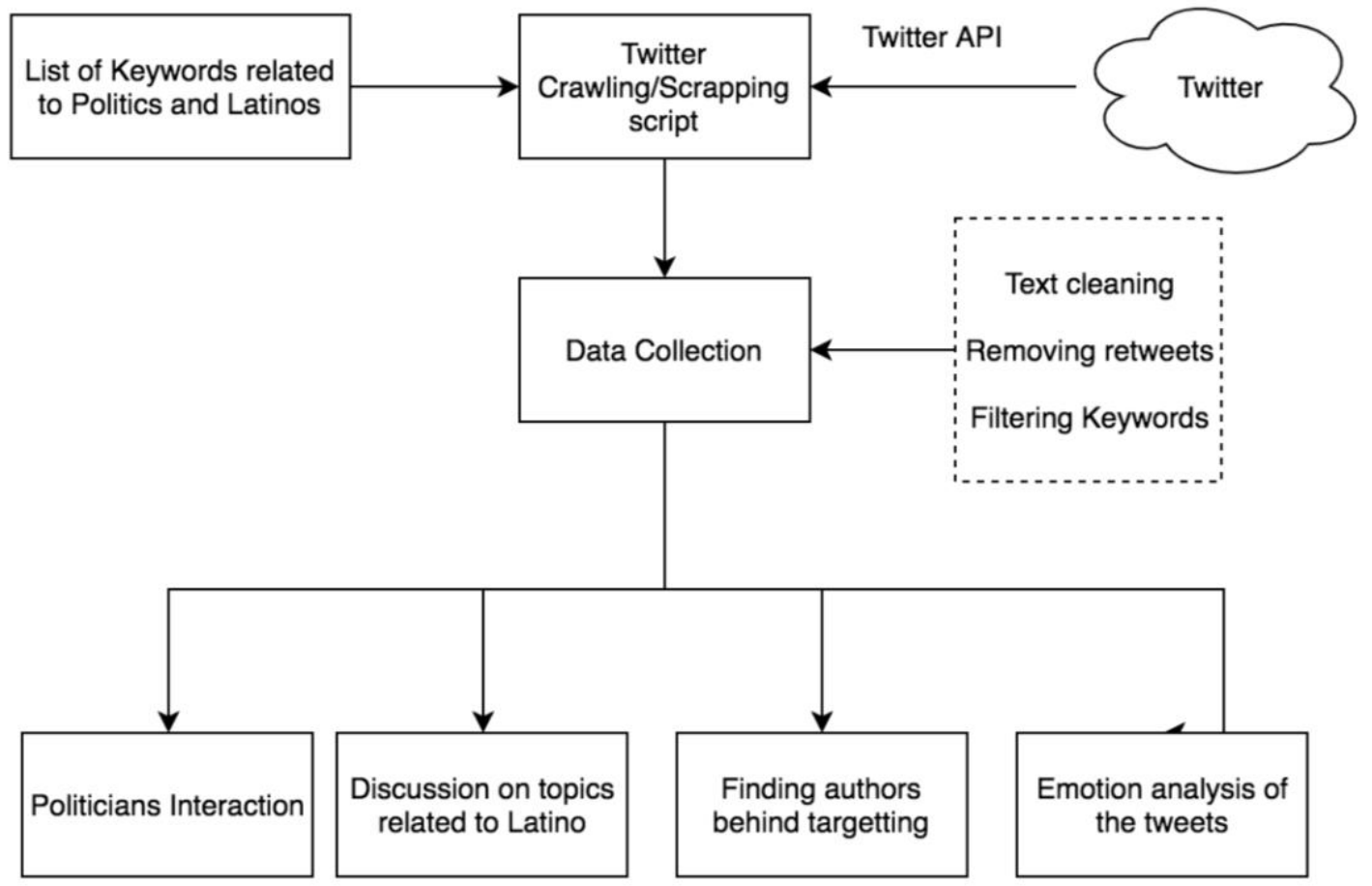

Figure 3.1.1 (a) Workflow of collecting data from Twitter

From the JSON that Twitter API sends back, it was necessary to cleane the data to only retain the required parameter for this study. Figure 3.1 shows the workflow of how tweets were collected and studied. From Twitter, parameters such as ID, text from the tweet, created date, number of favorites, number of retweets and the username of the tweeter were used. Figure 3.1.2 shows a snapshot of the cleaned data. 


\begin{tabular}{|c|c|c|c|c|c|c|c|}
\hline$\nabla$ & created_at & -4 & text & retweets $|\nabla|$ & favorites & $\nabla$ & user \\
\hline $1.04477 E+18$ & & $09 / 26 / 18$ & b'does not want them to return. Why? because those illegal & 0 & 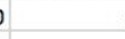 & 1 & wallybeaver771 \\
\hline 1.04477E+18 & & 09/26/18 & b'Mccaskills children are Hispanic children of David Esposito & 0 & 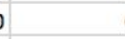 & 0 & wallybeaver771 \\
\hline 1.04475E+18 & & $09 / 26 / 18$ & $b^{\prime}|\times e 2| \times 80|\times 9 c|$ wish I could tell you Peppermint isn $|x e 2| \times 8 \mid$ & 0 & 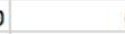 & 0 & annette \\
\hline $1.04474 E+18$ & & $09 / 26 / 18$ & b'Three proclamations today: Hispanic Heritage Month, Wa & 0 & 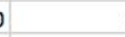 & 1 & Kenny Coble , $\ddot{A} C_{\text {" }}, \ell_{\text {, Éo }}$ \\
\hline $1.04474 E+18$ & & $09 / 26 / 18$ & b'RSVP today. Latino Creatives in Entertainment: writers, pre & 0 & 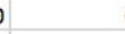 & 0 & NAMIC SoCal \\
\hline $1.04474 E+18$ & & $09 / 26 / 18$ & b'Proud to be working on @AARP @Univision partnership to & 1 & 1 & 3 & Chryste Hall \\
\hline $1.04474 E+18$ & & $09 / 25 / 18$ & b'\#RegisterToVote\n\#VoteRepublican\n\#LatinosForTrump〉 & 0 & 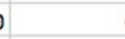 & 0 & Deplorable Redleg \\
\hline $1.04473 E+18$ & & 09/25/18 & b'For \#NationalVoterRegistrationDay, @HRC was on the gro & 9 & 2 & 29 & Human Rights Campaign \\
\hline $1.04473 E+18$ & & $09 / 25 / 18$ & b'@latinovictoryus The median household income for U.S. $h$ & 0 & ) & 0 & Deplorable Redleg \\
\hline $1.04472 E+18$ & & 09/25/18 & b'The multifaceted voter engagement partnership will focus & 0 & 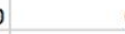 & 0 & Univision Careers \\
\hline $1.04472 E+18$ & & $09 / 25 / 18$ & b'@VictoriaBVicki@thomaskaine5 I live in an area of Dallas & 0 & ) & 0 & Bill Reyno \\
\hline $1.04469 \mathrm{E}+18$ & & $09 / 25 / 18$ & b"@jackappleby It's a complex topic. Quite a lot of people d & 0 & ) & 0 & Anime,ú ${ }^{\circledR}$ Girl,ú $\dot{u}^{\oplus}$ arcus,$i$ \\
\hline $1.04469 \mathrm{E}+18$ & & $09 / 25 / 18$ & b'A History of Anti-NAFTA Songs, From Gina Chavez to Rage & 0 & 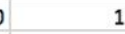 & 11 & billboard latin \\
\hline $1.04469 \mathrm{E}+18$ & & $09 / 25 / 18$ & b'@GrayConnolly @mattklewis The message that would se & 0 & ) & 0 & Bill David \\
\hline $1.04469 \mathrm{E}+18$ & & $09 / 25 / 18$ & $b^{\prime}$ \#Latinxs are the largest minority group in the U.S., yet we & 2 & ? & 2 & The Mujerista \\
\hline $1.04468 \mathrm{E}+18$ & & $09 / 25 / 18$ & b'Senator Diane Finestien must be replaced during the midte & 0 & D & 1 & JQCITIZEN10 \\
\hline $1.04468 \mathrm{E}+18$ & & $09 / 25 / 18$ & b'.@AARP \&amp; @Univision are teaming up to understanc & 4 & 4 & 4 & AARP Media Relations \\
\hline $1.04468 \mathrm{E}+18$ & & $09 / 25 / 18$ & b'@Dodlaughsatyou @jeffjmiller23 @elisabethlehem The o & 0 & 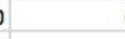 & 0 & TimW \\
\hline 1.04467E+18 & & $09 / 25 / 18$ & b'@Dodlaughsatyou @jeffjmiller23 @elisabethlehem Um... & 0 & ) & 0 & TimW \\
\hline 1.04467E+18 & & $09 / 25 / 18$ & b"NEW LOCATION: OIED Welcomes CURLY as the keynote: & 0 & ) & 1 & NC State OIED \\
\hline $1.04467 E+18$ & & $09 / 25 / 18$ & b'@KamalaHarris Please ask ur followers to check their statı & 0 & ) & 0 & Paula Royce \\
\hline $1.04467 E+18$ & & $09 / 25 / 18$ & b'According to the U.S. census, $59 \%$ White, $23 \%$ Black, $15 \%$ I & 0 & D & 0 & Dvkotv CVP \\
\hline
\end{tabular}

Figure 3.1.1 (b) A snapshot of Twitter data collected after cleaning the data

Also, only considering tweets and not any form of retweets from the user or the users' post

were considered. No contact was made with any third party to collect the tweets. We crawled through the Twitter page of different users using scrapping script if that user could provide us with more content regarding election and Latino. 5895 unique tweets from 3380 unique users were collected on Twitter after getting rid of all the retweets and tweets that did not involve topic regarding Latino and election together. Also, 6162 unique tweets from 7 Latino political candidates for midterm election 2018 were collected. The politicians and their total tweets can be seen in Table 3.2.

\begin{tabular}{|l|l|l|l|l|l|l|l|}
\hline Politicians & $\begin{array}{l}\text { Amanda } \\
\text { Renteria }\end{array}$ & $\begin{array}{l}\text { Ruben } \\
\text { Gallego(D) }\end{array}$ & $\begin{array}{l}\text { Carlos } \\
\text { Curbelo }\end{array}$ & $\begin{array}{l}\text { Norma } \\
\text { Torres }\end{array}$ & $\begin{array}{l}\text { Roza } \\
\text { Calderon }\end{array}$ & $\begin{array}{l}\text { Alex } \\
\text { Mooney }\end{array}$ & $\begin{array}{l}\text { Ted } \\
\text { Cruz }\end{array}$ \\
\hline $\begin{array}{l}\text { Total } \\
\text { Tweets }\end{array}$ & 1632 & 774 & 952 & 977 & 945 & 407 & 822 \\
\hline
\end{tabular}

Table 3.1.1: Number of tweets collected for political candidates under study 


\subsubsection{Collecting Reddit data}

After searching the keywords on Reddit, it was clearly found that the posts in Reddit came from six different political subreddits: r/Ask_Politics, r/Politics, r/News, r/True_News, r/Political_Humor, r/The_Donald, r/Democrats, r/Republicans. Reddit API was used to get all posts from these six subreddits posts. From these six subreddits, 1463 unique posts from 968 unique users were collected.

\begin{tabular}{|c|c|c|c|c|c|c|c|}
\hline author & totalPosts & avgScore \lfloor & totalScore $\nabla$ & MaxScorelnAPo $\nabla$ & $\mid$ avgComm $\nabla$ & totalComn $\nabla \mid$ & MaxCommentsInAPost $\downarrow \nabla$ \\
\hline therecordcorrected & 107 & 40.7663551 & 4362 & 473 & 4.5046729 & 482 & 54 \\
\hline ihatejoemcCarthy & 56 & 19.9464286 & 1117 & 409 & 2.73214286 & 153 & 37 \\
\hline asiatrails & 29 & 200.103448 & 5803 & 3223 & 4.96551724 & 144 & 49 \\
\hline Ivaginaryfriend & 13 & 2543.38462 & 33064 & 3679 & 33.1538462 & 431 & 92 \\
\hline PennSkinsFan & 13 & 3.53846154 & 46 & 7 & 0.38461538 & 5 & 1 \\
\hline Deathstalker1776 & 11 & 728.909091 & 8018 & 3053 & 17.9090909 & 197 & 65 \\
\hline only-read-headlines & 9 & 601.777778 & 5416 & 4078 & 93.2222222 & 839 & 699 \\
\hline bobadobalina & 9 & 495.111111 & 4456 & 3616 & 19.3333333 & 174 & 148 \\
\hline RyanSmith & 9 & 87.2222222 & 785 & 246 & 8.77777778 & 79 & 37 \\
\hline 9magsz & 9 & 82.8888889 & 746 & 353 & 46.3333333 & 417 & 111 \\
\hline anutensil & 9 & 37 & 333 & 111 & 5.44444444 & 49 & 27 \\
\hline skepticalspectacle 1 & 9 & 17.3333333 & 156 & 46 & 1.11111111 & 10 & 4 \\
\hline PoliticsModeratorBot & 8 & 15588.125 & 124705 & 33744 & 4367.25 & 34938 & 12323 \\
\hline DanWofSoc & 8 & 3190.875 & 25527 & 4499 & 48.75 & 390 & 118 \\
\hline pendulumislander & 8 & 542.75 & 4342 & 3991 & 16.625 & 133 & 104 \\
\hline traunkss & 8 & 57.125 & 457 & 314 & 65.875 & 527 & 260 \\
\hline Lack-of-Focus & 8 & 34.5 & 276 & 55 & 2.625 & 21 & 5 \\
\hline oblivionrecurs & 6 & 26.6666667 & 160 & 42 & 3.33333333 & 20 & 7 \\
\hline US2A & 5 & 3805.8 & 19029 & 4406 & 899.2 & 4496 & 1833 \\
\hline
\end{tabular}

3.1.2 A snapshot of Reddit data collected after cleaning the data

Table 3.1 shows all the data collected from both the social media. Quantitative content analysis was done of posts in Reddit and tweets from Twitter related to the midterm election and Latinos. Both qualitative and quantitative methods of analysis were used for this problem. This mixed-method approach enables the case studies to speak to concerns at the intersection of several disciplines: especially those focused on social science, and computer science. Table 3.1.2 shows all the data collected from both the social media. 


\begin{tabular}{|l|l|l|l|}
\hline & Twitter & & Reddit \\
\hline Tweets & 5894 & Posts & 1463 \\
\hline Users & 3380 & Users & 968 \\
\hline Favorite & 103028 & Score & 851,628 \\
\hline
\end{tabular}

Table 3.1.2: Total post collected after cleaning data for both the social media account

\subsection{Learning how Latinos were targeted}

With all attention going towards Latino community for the midterm election and for the upcoming presidential 2020 election, it seems that Latino crowd have a huge advantage to swing the votes. To answer the broad question of how this Latino community were targeted online during the midterm election, the following questions were designed to be answered:

- How different topic were involved when targeting Latinos?

- Who were the people targeting Latinos?

- How emotions where shared by the users talking about Latinos and how Latino candidates interacted online?

These questions would help better understand how Latino candidates were eager to mobilizing the crowd by interacting with them. Also, it would understand how the topics related to Latinos were being discussed on these social media platforms. Apart from this, it would find prominent voices that were targeting the Latino community and if those voices were focusing on sharing information through the use of emotions. 


\subsubsection{Targeting Latino crowd through Twitter}

The motive here is to focus on how Latino crowd are being targeted by different actors and what topic are of interest to these Latino community. It was also of interest to know how the people involved around these topic share emotions in their tweets and how the Latino politicians interact with their audience.

\subsubsection{Understanding how the Latino community were targeted overtime on Twitter}

The study wanted to know when and how much people were posting about and targeting Latino community around political topics on Twitter over a period of one year under study. To study this, a line graph was plotted with the total number of tweets in Twitter tweeted per day. The topics that were discussed that involved Latino community related to midterm could then be analyzed. To decide on the major topics discussed, highest frequency of words that were used at the time were calculated, where we could see spikes on the graphs.

\subsubsection{Understanding who were the people targeting Latino community on Twitter}

Here, the goal was figuring out who are the main people driving conversations revolving around Latino community and election. The aim was to find out individuals who tweeted about topics regarding Latino and midterm and received a wide range of attention from other users in the same platform. From the Twitter data, total tweets from a user vs their popularity (favorite count) among other users was plotted. 


\subsubsection{Understanding level of emotions shown by people and interaction show by Latino politicians}

The goal here is to understand how much emotional words people used to share their information regarding politics and Latino before the midterm election. This would give a better understating if Latino community were targeted with an intent to target their emotions that they demonstration towards the current government. This would also help identify if anyone was trying to connect emotionally with the Latino community regarding politics. Using a repository of positive and negative words that most popular language processing uses, the total number of positive and negative words used by each user for all of their collected tweet was calculated. As some of the users were tweeting throughout the year and some only a few times a year, the average number of emotional words used per tweets was calculated. From the data collected and calculated, a graph of the average number of emotional words used per user's total posts was plotted.

Not only observing emotions but, it was necessary observe how Latino candidates interact with other accounts online through their Twitter account. Most of the candidates are firsttime candidates for the midterm elections [12]. For fairness, candidates are from both Democrat and Republican parties. Most of the candidates had individual account and account created to promote themselves for the election. Only the account with the highest number of followers between the two was considered. Data was collected from Twitter API for all the chosen Latino candidates' popular Twitter accounts. Interaction with other accounts as as defined as mentions of the other account on candidates' tweet. In Twitter, a mention is started with “@” followed by the username. The data were then divided into two types for all the candidates: user's interaction and message broadcast, based on the criteria that a tweet text has “@” present on it. The total types of tweet for each individual account was then plotted. 
Figure 4.1.1 shows how Latino political candidates for this midterm election have been using their Twitter to reach out to other users.

\subsubsection{Targeting Latino Crowd through Reddit}

Looking at subreddit threads from Reddit posts that were able to generate a lot of attention among Reddit users. Since there are no word limitation and people can post information from anywhere about a specific topic, it is important to study the targeting happening on Reddit. The study looks at the topic these subreddits discussed a lot about relating to Latino community and also look at people that could get high scores (likes and dislikes) on their posts.

\subsubsection{Understanding how the Latino community were targeted overtime on Twitter}

The goal is to know when and how much people were posting about and targeting Latino community around political topics on Reddit over a period of one year under study. To study this, a line graph with the total number of posts posted in subreddits of Reddit per day was plotted. The spikes seen on the graph were analyzed and the topic related to those spikes that was able to generate such high number of posts within short period of time were studied. To decide on the major topics discussed, the highest frequency of words that were used at the time where we could see spikes on the graphs were calculated. 


\subsubsection{Understanding who were the people targeting Latino community on Twitter}

The goal is to find out the people who are posting some of the most famous post on such subreddits revolving on topic related to election and Latino community. From the Reddit data, total posts from a user vs their popularity (score) among other users was plotted. 


\section{Chapter 4}

\section{Data Analysis and Results}

One year of tweets and posts from Reddit and Twitter were collected, to uncover how much people were targeting Latinos around political topics on social media. The study made an effort to uncover who was driving these conversations. The data collection took a snapshot of all activity starting from September 24, 2017, until September 24, 2018.

\subsection{Targeting on Twitter}

\subsubsection{Understanding how Latino communities were targeted overtime}

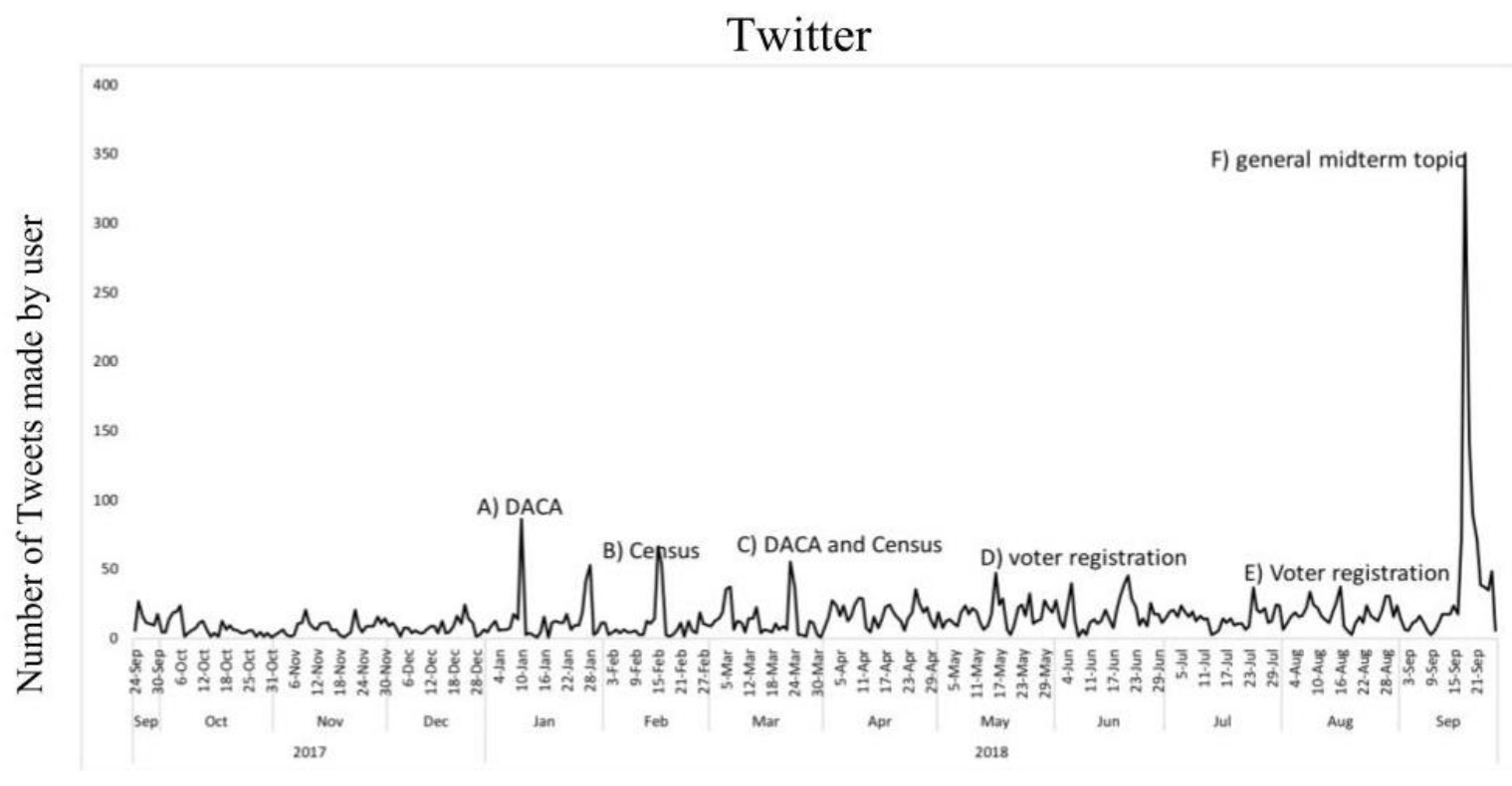

Tweets Created at

Figure 4.1.1: Overview of peoples posting behavior for content related to Latino and midterm in Twitter 
Here the goal is to understand what kind of information related to topics revolving around politics is being shared with Latino on the said social media platform. A graph to show the total number of tweets and posts mad per day on each platform was plotted. Figure 4.1.1 shows the total number of tweets made per day. The $\mathrm{X}$-axis represents the date the post was posted on the social media platform and the $\mathrm{Y}$-axis represents the number of posts made on that day.

Figure 4.1.1 shows that information sharing regarding Latinos and elections started massively increasing from September 2018. However, there are noticeable political topics about which information was shared before that. The first peak on Jan 2018 (point A) on the chart were information shared which discussed DACA (Deferred Action for Childhood Arrivals). This was a relevant topic to discuss since Trump's administration decided to stop DACA on September 5, 2017 [45]. Here it is seen from the data that many NGOs working for Latinos started tweeting about this and hence the small spike. The discussion appeared to revolve about the impact that eliminating DACA would create in Latino community and were encouraging Latinos to renew their DACA application. In the Twitter graph, a second and third small spike on Feb and March 2018 (point B and point C) can be observed. The tweets on these dates were mostly information around what it might mean to add a citizenship question on the 2020 Census and what its consequences could be to immigrants and about DACA. The fourth small spike seen on May 2018 (point D) had also information shared regarding DACA. However, this time, a small portion of tweets urging Latinos to register to vote for the midterm election and how the Latino community could have the power to impact the results of the election through voting can be noticed. 
If change is what you want, you have to vote. Get engaged and spread the word. If you have not yet registered to vote or want to help spread the word, visit powerof18.com \#PowerOf18'

The fifth spike on the graph which is on August 2018 (point E) were information shared around voter registration and the challenges Latinos have been experiencing regarding this issue. A tweet that talked about high school students who were not allowed to register to vote in Texas even though they had everything in order and ready [46] was one of them. Here most of the NGO's were sharing information that informed Latinos of their rights if DACA ended to help them thrive in the US:

“Questions about what Trump's \#DACA decision means? Check out this video and know that you still have rights. https://t.co/MYIQYytL7J"

The final peaks on Sep 2018 (point F) discuss mostly around topic revolving around the midterm election. Here lot of users participating in the discussion about the midterm election can be seen.

\subsubsection{Understanding who were the people targeting Latinos}

The aim was to uncover who were the main people driving conversations around Latinos and the election. For this purpose, a graph with the total number of tweets a particular user generated vs their popularity was plotted. The X-axis in Figure 4.1.3 represents the total number of tweets made by each user. The Y-axis represents the total popularity of the user's tweets or posts combined (number of upvotes or favorites). Each point in Fig. 4.1.3 represents a user on Twitter 


\section{Twitter}

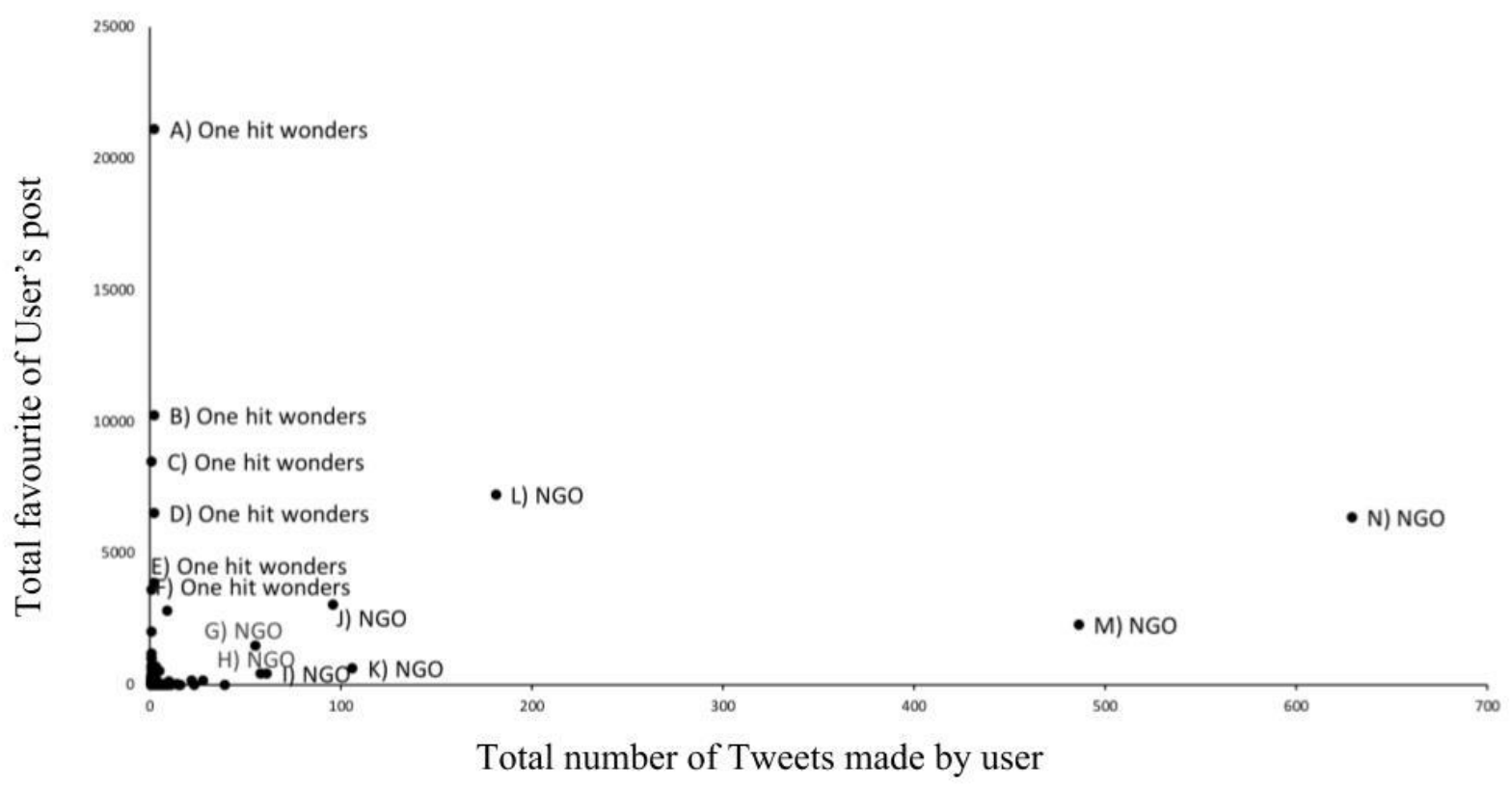

Figure 4.1.2: Overview of how much each individual posted on Twitter and the interaction they received from other users

For Twitter, the most active users were identified by finding those individuals whose favorite count or number of posts was higher than three times the standard deviation (normal procedure to find outliers). These active users (they are each labeled with a letter) were then profiled. The type of topics that they mentioned in their content was then analyzed.

On Twitter, two distinct types of behaviors adopted by highly active users were identified:

- Type A ("Pro-Trump one hit wonders"): This group (11.1\% of the active users) was confirmed primarily of celebrities who with few tweets about any topic received massive attention from the public. A tweet from a user in this group saying how Trump has been working for Latinos received massive attention from audiences. One Twitter user who posted only two tweets related to Latinos and elections but had the 
highest level of engagement from audiences: 21,149 favorites in total and 6,197 retweets. It was noted that all of the Tweets from these individuals supported president Trump's policies. Hence, this level of engagement and behavior led to naming people in this group the "Pro-Trump one hit wonders".

One particular user in this cluster was talking about how Latino household income increased in 2016 and 2017 due to Trump's policies and shared a link to a news article about the topic. This user used to work for Fox News, a network well known for its support to Donald Trump [40]. One of the user's tweets read:

"I am a proud Hispanic woman, “... "I'm really proud to say this president has created a big tent. There is room for everyone."

- Type B ("Pro-Latino NGOs"): All of the users in this group (88.9\% of active users) belonged primarily to NGOs. The NGOs discussed political events sporadically and focused on helping Latinos to obtain better work opportunities. For this reason, this group is called "Pro-Latino NGOs". $87.5 \%$ of these active users referenced primarily the topic DACA. On average, $30 \%$ of the tweets of these accounts mentioned DACA, $27 \%$ the Latino community, less than $1 \%$ the US census and citizenship questions for voting in the midterm elections. Two NGOs (Voto Latino, Mi Familia Vota) were the ones that contributed most of the content for this group. A sample tweet:

"RENEW YOUR DACA ASAP! Call us at 844-411-DACA (3222) for real-time information on DACA renewals, resources in your community and more! DREAMers" 
Apart from that, other of the accounts present in this group came from different selfdefined political organizations, such as Hispanic Caucus, MALC. Their main aim has been increasing the Latino voters during this midterm election and fighting the separation of Latino families. However, these accounts rarely discussed voting rights of Latinos. They focused more on encouraging people to register to vote for the midterm elections and have strongly been fighting to protect DACA.

\subsubsection{Understanding level of emotions shown by people and interaction shown by Latino politicians}

The goal here was to understand how emotions can be used to relate to people's political opinion and mobilize them. For this purpose, Figure 4.1.3 (a) shows an average number of emotional words used by a specific user on their Tweets for the time period under study. The study identified the most emotional tweeters by finding those users whose average number of emotional words in their tweet was higher than three times the standard deviation (normal procedure to find outliers).

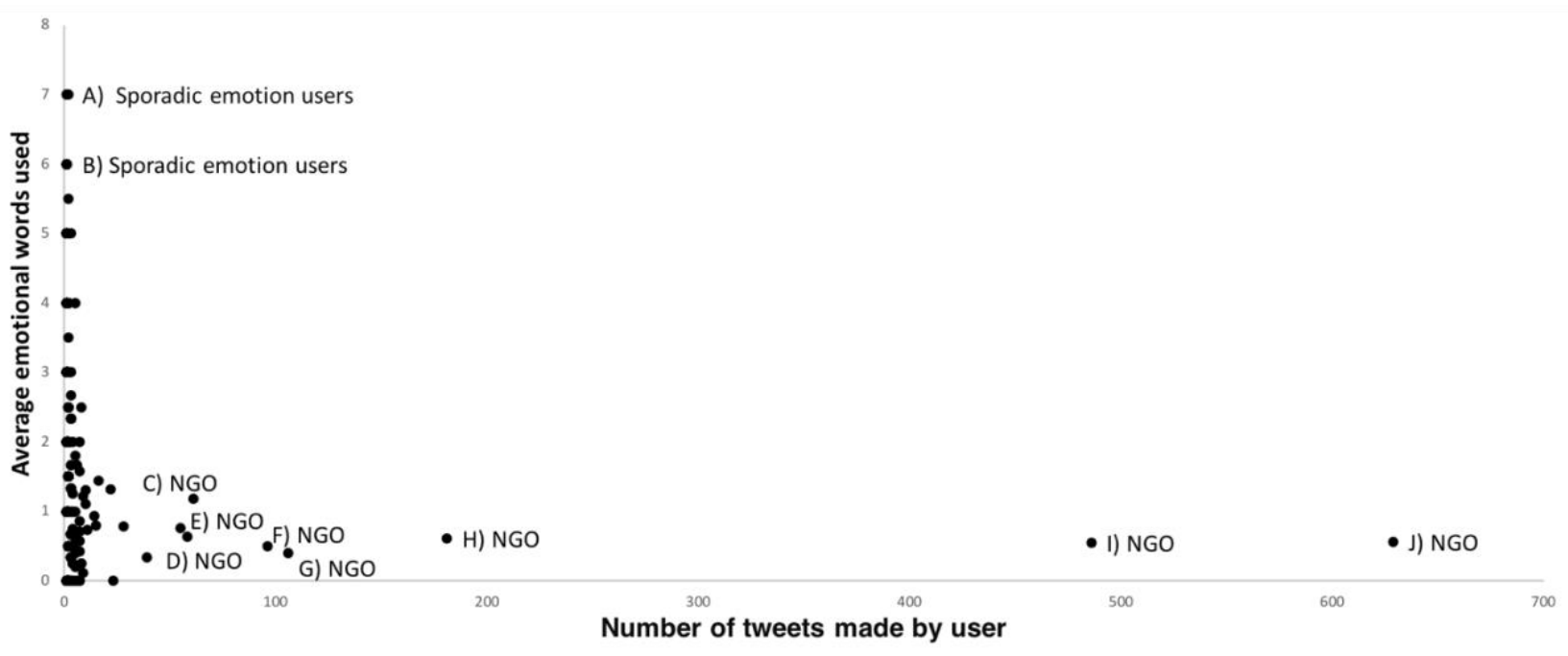

Figure 4.1.3 (a): Overview of user's average number of emotional words used on Twitter 
Two distinct clusters from the figure were found:

- Type A (Sporadic Emotions): This group (55.5\% of the most emotional tweeters) had used a lot of emotional words used compared to the number of tweets they tweeted. Hence, this group has been "Sporadic Emotions". This group was primarily composed of regular users and tweets both for and against the current government were found. This was expected out of the group as regular users would tweet regarding both sides.

- Type B (Pro-Latino Emotions): This group (45.5\% of the emotional tweeters) had many emotional words used but also had lots of tweets posted. So, the average number of tweets per post might be less but the overall use of emotional words to describe the political situation was high and continuous over the period of study. Hence, the name of the group is "Pro-Latino Emotions". Unlike, Type A, where the tweeters were regular users, this group was full of political NGOs. What is interesting is they are usually talking about a sensitive topic using lots of emotions. And the group were using emotional words to aware people of topic regarding DACA and midterm. An example tweet can be seen below:

"Nobody will ever deprive the American people of the right to vote except the American people themselves and the only way they could do this is by not

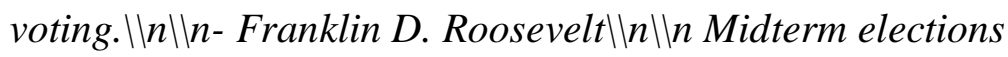

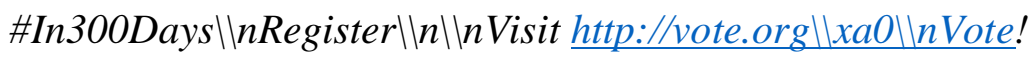




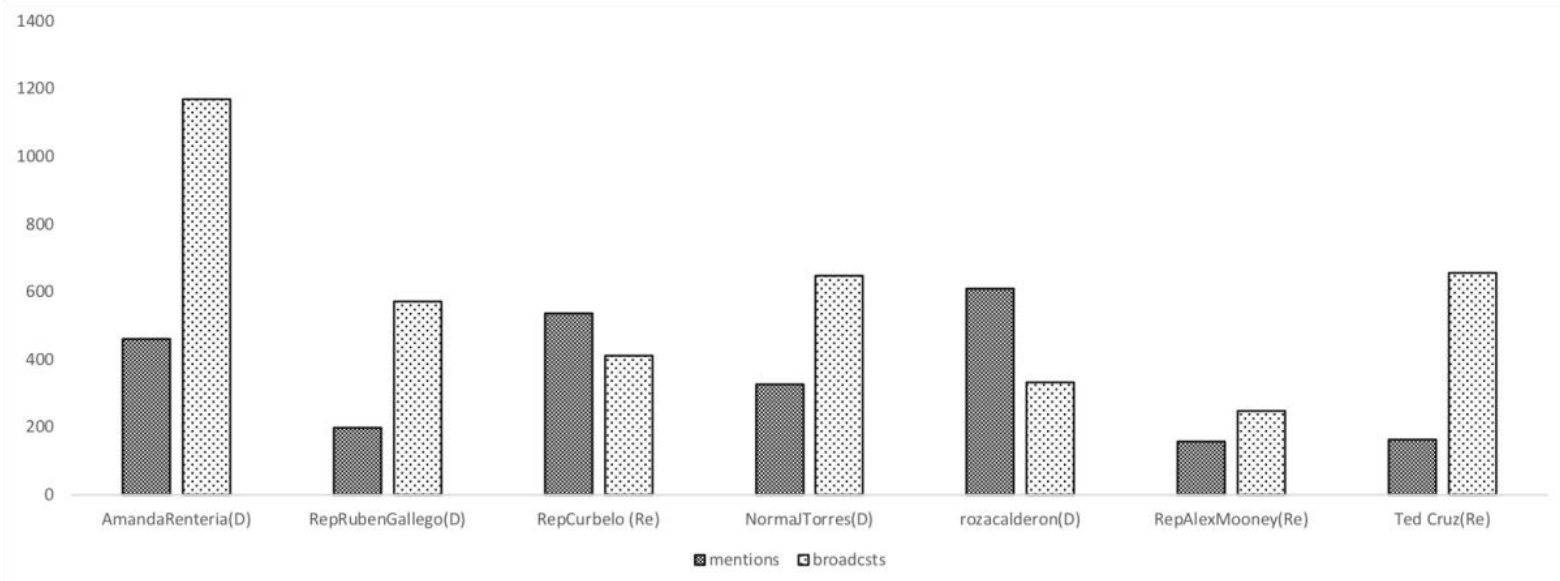

Figure 4.1.3 (b): The number of tweets where Latino politicians interacted vs number of tweets dedicated for broadcast

The goal was to analyze how Latino candidates interacted to other accounts over a course of 1 year. Figure 4.1.3 (b) shows the total number of mentions in their account and the total number of tweets just as message sharing or broadcasting. The study shows that how they interacted with the public did not depend on whether they are democrats or republicans. 5 out of the 7 politicians under study emphasized broadcasting messages to the public instead of interacting with them. Interestingly though, the politicians who emphasized interacting with public did not win during for the positions they were running for. It was the candidate's party or the candidate himself winning the position. 


\subsection{Targeting on Reddit}

\subsubsection{Understanding how Latino communities were targeted overtime}

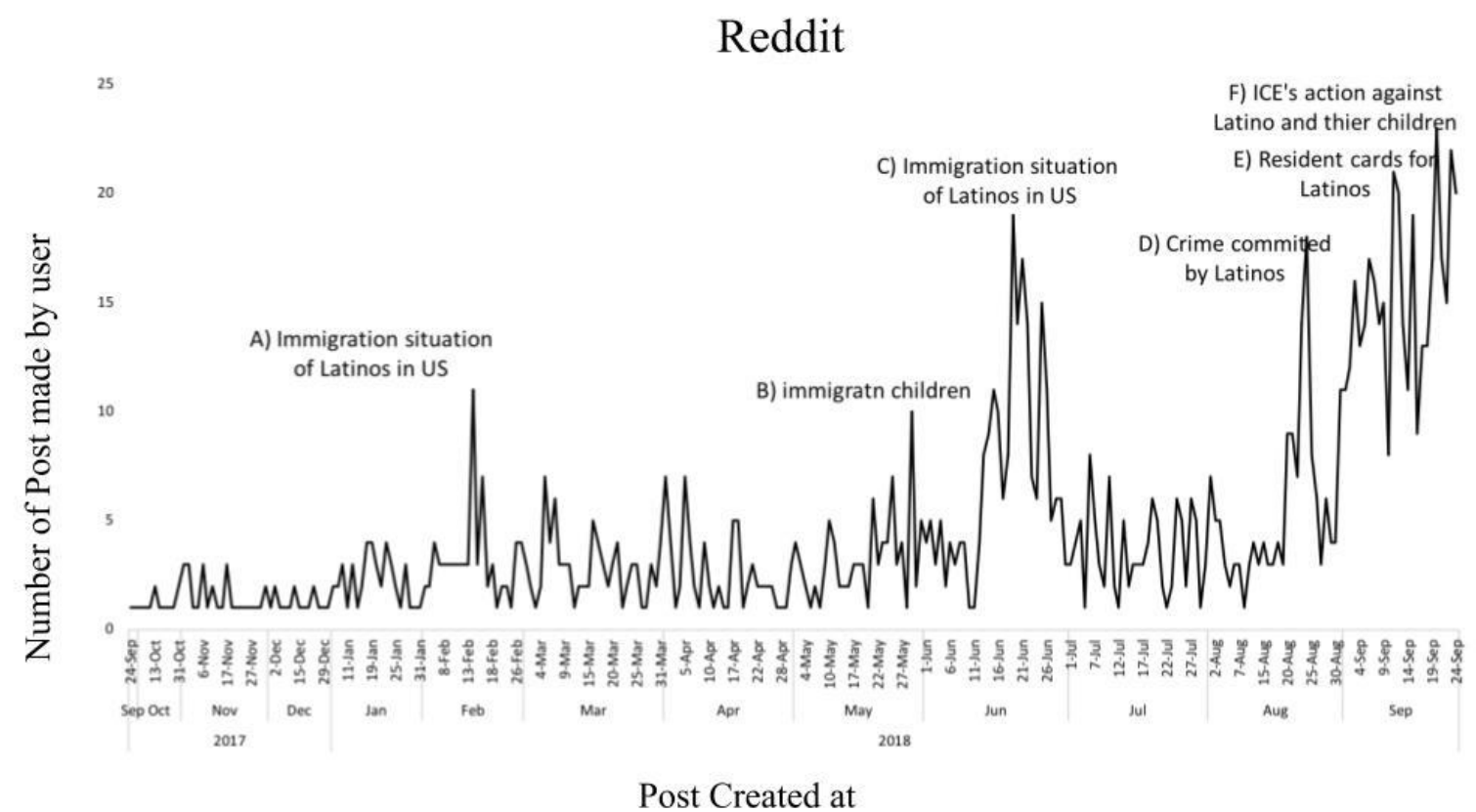

Figure 4.2.1: Overview of peoples posting behavior for content related to Latino and midterm in Reddit

Looking at figure 4.2.1, on Reddit information sharing regarding Latinos and elections increased very early on in the year (February 2018). From February 2018, there was information sharing through Reddit post about the primaries in Texas.

Most of the peaks on Reddit were discussions around immigration issues. For instance, on February 14, 2018 (point A), there is a spike on posts tweeting about immigration. This coincides with the open-ended debate on immigration that started on the Senate the evening before and stalled on Tuesday when Democrats objected to the Republican's first amendment, which would punish so-called sanctuary cities. 
On Reddit, there was evidence of an immigration debate happening before and after the Senate debate took place via mega-threads and AMA's. A mega-thread is a thread initiated by a moderator of a subreddit, to organize the community and initiate political discussions. AMAs (Ask Me Anything sessions) are special threads where users can ask any questions they want to celebrities and high-profile individuals, in this case, users from Reddit invited mainly politicians. These kind of post on Reddit grabbed a lot of attention from users and also invited them to share their views online and with such high-profile individuals. People were very responsive on these posts.

On May 29,2018 (point B) the conversation revolved around the treatment of children separated from undocumented immigrant parents at the border. This topic which continued to generate debate on the platform. Such topics were of highly discussed on Twitter as well. The spike on June 19, 2018 (point C) talked about state and federal lawmakers who were denied entry to a shelter in Florida, posts creating uproar over the federal government's break-up of families caught illegally crossing the U.S. On September 11, 2018 (point D) there was a peak related to conversations around the murder of a teen in New Jersey allegedly by an illegal immigrant. Here there were much information shared discussing and encouraging others to support building the US Border wall and stopping illegal Latinos from entering the US. The top posts on September 20 and September 23,2018 (point E to point G) informed about the policies Trump had proposed around immigrants, such as restraining green cards for immigrants on public aid and moving \$260M from cancer research HIV/AIDS and other programs to cover the costs of taking custody of the children of immigrants. 


\subsubsection{Understanding who were the people targeting Latinos}

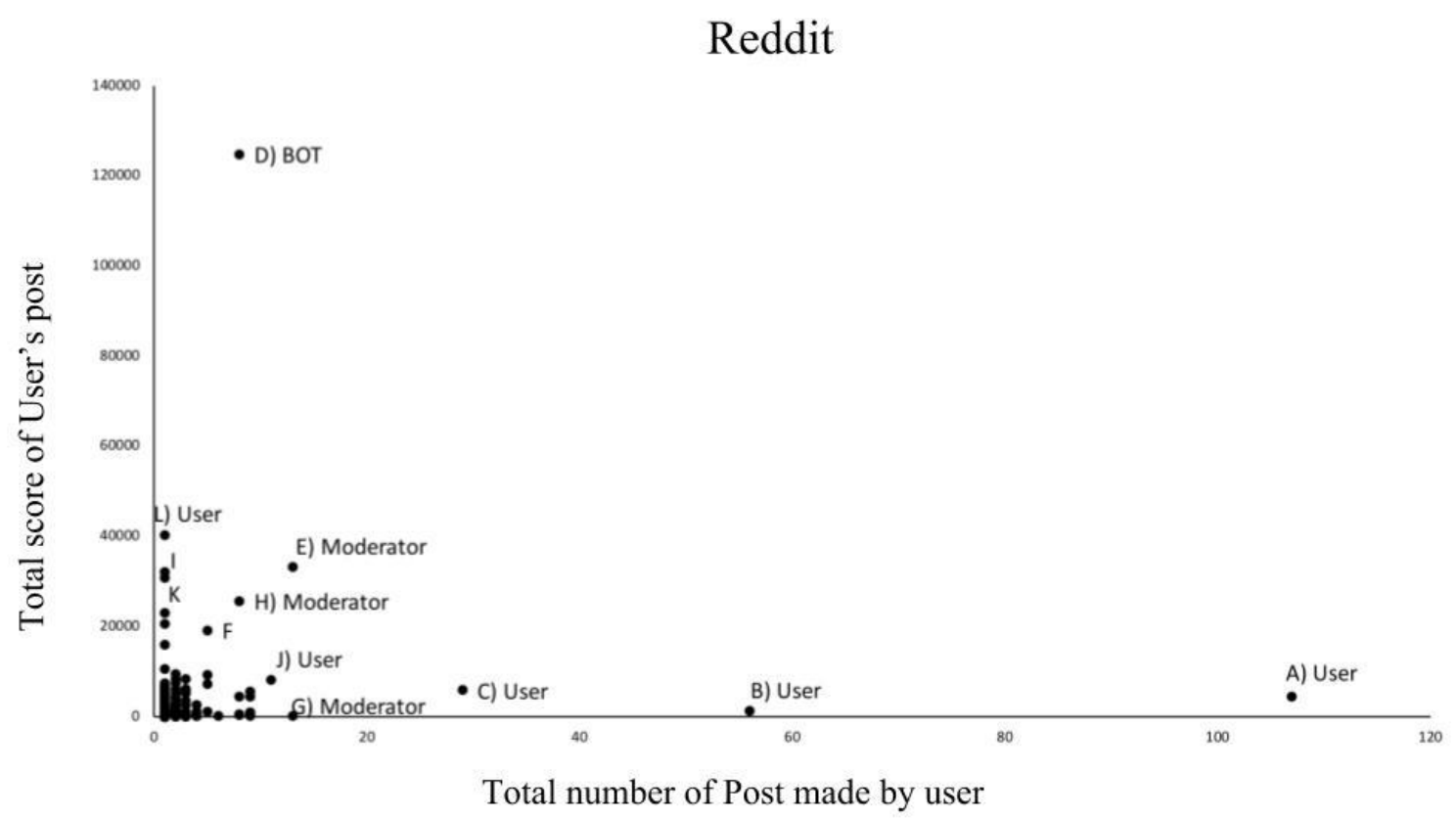

Figure 4.2.2: Overview of how much each individual posted on Reddit and the interaction they received from other users

On Reddit (see Figure 4.2.2) the most active users were identified and profiled. It was possible to identify three distinct behaviors in the most active:

- User Type A ("Pro-Latino"): All users in this group (16\% of the highly active users) referenced primarily the overall migratory situation of Latinos in the U.S. Much emphasis was given by people on this post to consider president Trump as racist and anti-immigrant person. These behaviors led this group to be called "Pro-Latino". On average, $26 \%$ of all the Reddit posts that these users made discussed how Trump was racist, and how he was cruel and inhuman by separating immigrant children from their parents at the border. A sample post that people from this group shared: 
“Gratuitous cruelty by Homeland Security: Separating a 7-year-old from her mother - WHAT EXACTLY did a 7-year-old Congolese girl do to the U.S. to deserve the trauma that has been visited upon her including forcible separation from her mother by DHS Secretary Nielsen and her immigration agents?"

- User Type B ("Pro-Trump"): All authors in this group (41.5\% of most active users) belong to r/The_Donald, a community known for its political trolling behavior [10]. Their posts focused on mobilizing people to vote Republican (pro-Trump) in the midterm elections. Hence this group is called "Pro-Trump". The mobilization seemed a lot successful by the popularity received by posts generated as mega-threads where they had deep discussions with others on Reddit. These mega-threads occurred at least once per week. These people were the ones who also organized AMAs with candidates and politicians participating in the midterm elections. An example of one of their posts read:

"If you are a congressional candidate and are interested in holding an AMA(Ask Me Any-thing) on r/The_Congress, please contact The_Donald moderators by clicking the contact link on our sidebar"

All of these active users posted about the current immigration situation of the United States and occasionally posted news about crimes that illegal immigrants had done. The people in this cluster also tend to post jokes about illegal immigrants. There was also a tendency to use such news reports to show special favoritism towards Trump and his decisions relating illegal immigrant: 
"Dad's grief leads to quest to count deaths caused by illegal immigrant drivers. In the wake of a 2013 study by the California Department of Motor Vehicles that concluded that unlicensed drivers are almost three times as likely to cause a deadly car accident as a licensed driver."

- User Type C (“The Information Referees"): This group (41.5\% of the most active users) had a more neutral view on the topic of Latinos and their rights in the U.S. They primary posted news reports from sites that are known share information without taking any sides or being biased. People in this group shared posts where fake news regarding Latinos was debunked. For this reason, the group is called "The Information Referees". But the majority of the posts here, $35 \%$ of the posts, were mega-threads where they discussed the political ecosystem in general (without supporting democrats or republicans). An example:

"Breitbart fabricated fake story that illegal immigrant started deadly Sonoma wildfires says Sherriff"

\subsection{Comparing the target directed towards Latino community on Twitter and Reddit}

Looking at the data analysis from Twitter, it can be seen that the main people driving conversations around Latinos on Twitter where celebrities who posted few tweets and gained massive attention. And on the data, such tweets were highlighting the positive things that the US president Trump has done with Latinos. However, NGOs focused on discussing issues related to Latino immigrants who had been long-term in the US, such as dreamers or Latinos who had managed now to should their citizenship. These NGOs' accounts tended to discuss 
less about current political events. However, not a single way to mobilize people were seen on Twitter. Hence a study of a social media website where people can post information from all around the web about a specific top like politics, was indispensable to study the impact of such target on mobilization of a crowd.

Hence, after studying data from subreddits talking about politics on Reddit, it was easy to recognize that the majority of the most active (almost 50\%) were individuals who participated within political trolling communities. They had diverse activities for mobilizing people to vote Republican, including being able to discuss directly with real political candidates, and had mega-thread discussions regularly. They also appeared to create digital propaganda by actively sharing photos of Latinos supporting Trump.

Comparing these two platforms, on Twitter the information shared around the topic of Latinos and elections started to grow much later than on Reddit, where it started since early February 2018. On Reddit they had diverse dynamics to mobilize people in discussions and to share information, such as the mega-threads or the AMA dynamics. On Reddit, the discussions and information sharing regarding political events and Latinos appeared to have been much steadier and more continuous. While on Twitter it was more sporadic and mainly around registering to vote. But not discussing other political events occurring (such as the primaries, or policies that might directly affect them, e.g., the policies around green card holders.) On Twitter, there were also fewer discussions about new illegal immigrants. We also note that on Reddit there were not many discussions around the problems that Latinos face when trying to register to vote. 


\section{Chapter 5}

\section{Designing Civic Tech to Target and Mobilize Latinos}

The number of Latinos present in the US who are eligible to vote makes it extremely important to properly mobilize that crowd for fair and unbiased election. NGOs have a great window of opportunity for mobilizing Latinos to be more involved in politics. Previous research has shown that taking the time to explain the political ecosystem to individuals is important to mobilize them in political causes [10]. With the result of the midterm election and lots of attention going to increase in Latino voter's turnout [48], this has even been more of a concern for the next election of 2020. The way in which there have been different trolling information shared online regarding Latino and in no way a proper way to mobilize Latinos, a case study is shared where a bot shares information which could motivate Latinos to take actions themselves.

In the study, it can be observed that NGOs did not seem to focus on mobilizing Latinos. Only republican partisans used celebrities to potentially mobilize Latinos in their favor. While NGOs might not be able to favor one particular party or candidate, they could still consider partnering with Latino celebrities that can help them to better engage with Latinos in the U.S. Lack of socialization among different Latino communities from Mexico, Puerto Rico, Cuba comes as a big hindrance when trying to address the Latino community as a whole. 


\subsection{Bot to mobilize Latino crowd to engage in politics}

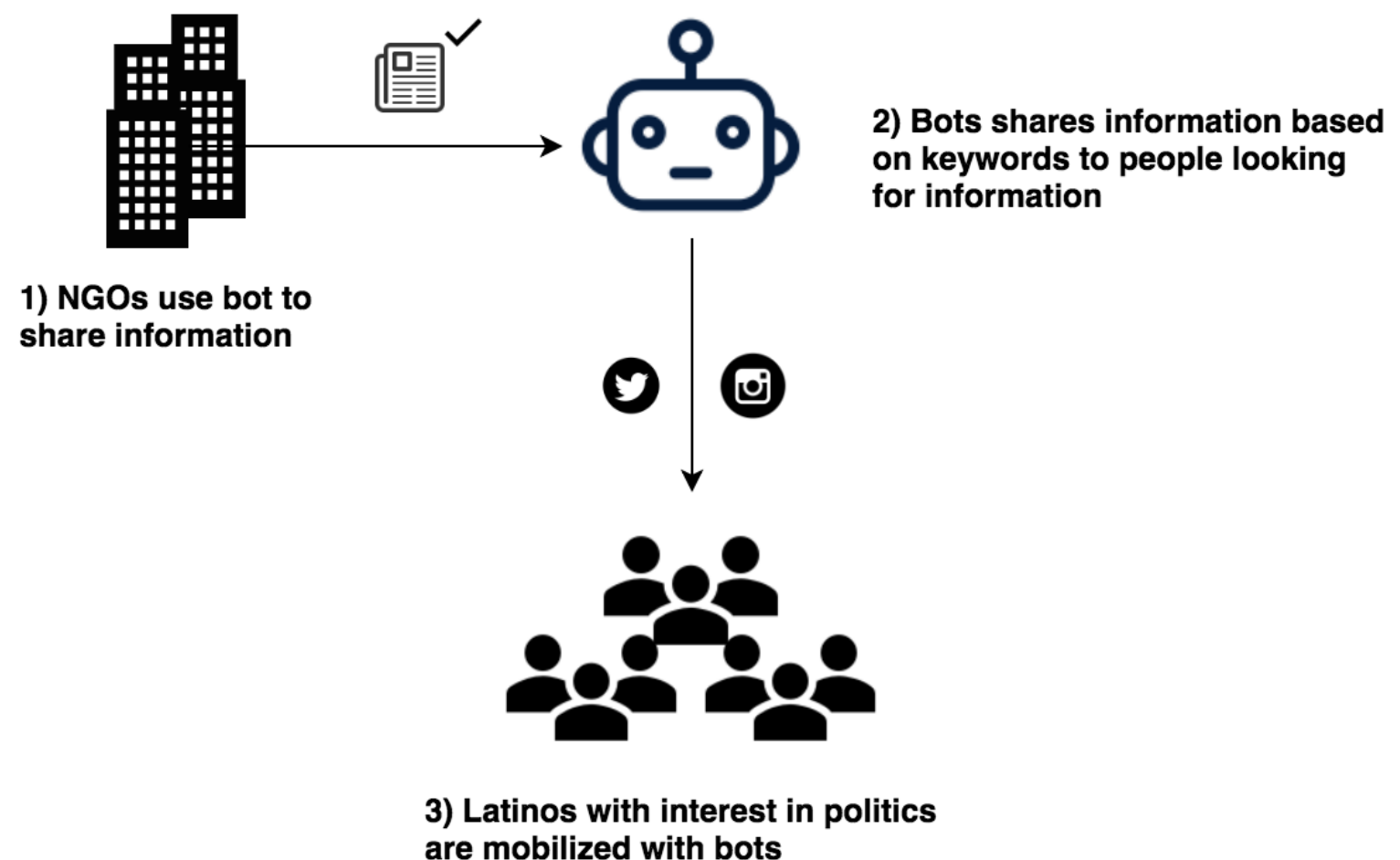

Figure 5.1: Workflow of how NGO can use bot to share information

It can be important for NGOs to adopt more strategies for explaining the current political ecosystem to Latinos. Especially, to make an effort to cover all political events related to Latinos and perhaps even to adopt strategies that will facilitate deep discussions (similar to those used by political trolls). It is important that NGOs take actions to actively debunk misinformation regarding Latinos, such as fake news reports about crimes done by illegal immigrants. Figure 5.1 shows an approach NGOs can adapt to mobilize the crowd.

As voting for any kind of political election once increases the change of voting again in other elections, which in long run can become a voting habit [37], mobilizing the Latino crowd for 
this change is a bigger issue that is seen. And the efforts seen from these NGO's are more of towards motivating the crowd than mobilizing them.

Given what the study found on Reddit, where citizens actively debunked fake news ("the information referees"), perhaps the NGOs and normal citizens could collaborate to have an army of people to help them identify and debunk misinformation and use bots to share these information to Latino crowd interested in politics. Relating the work above, the Latino crowd here have the ability to vote and are motivated to bring important changes in the government too but all they require now are the signal triggers which would be able to bring them to the election polls for a good cause. These signals could be generated through these bots.

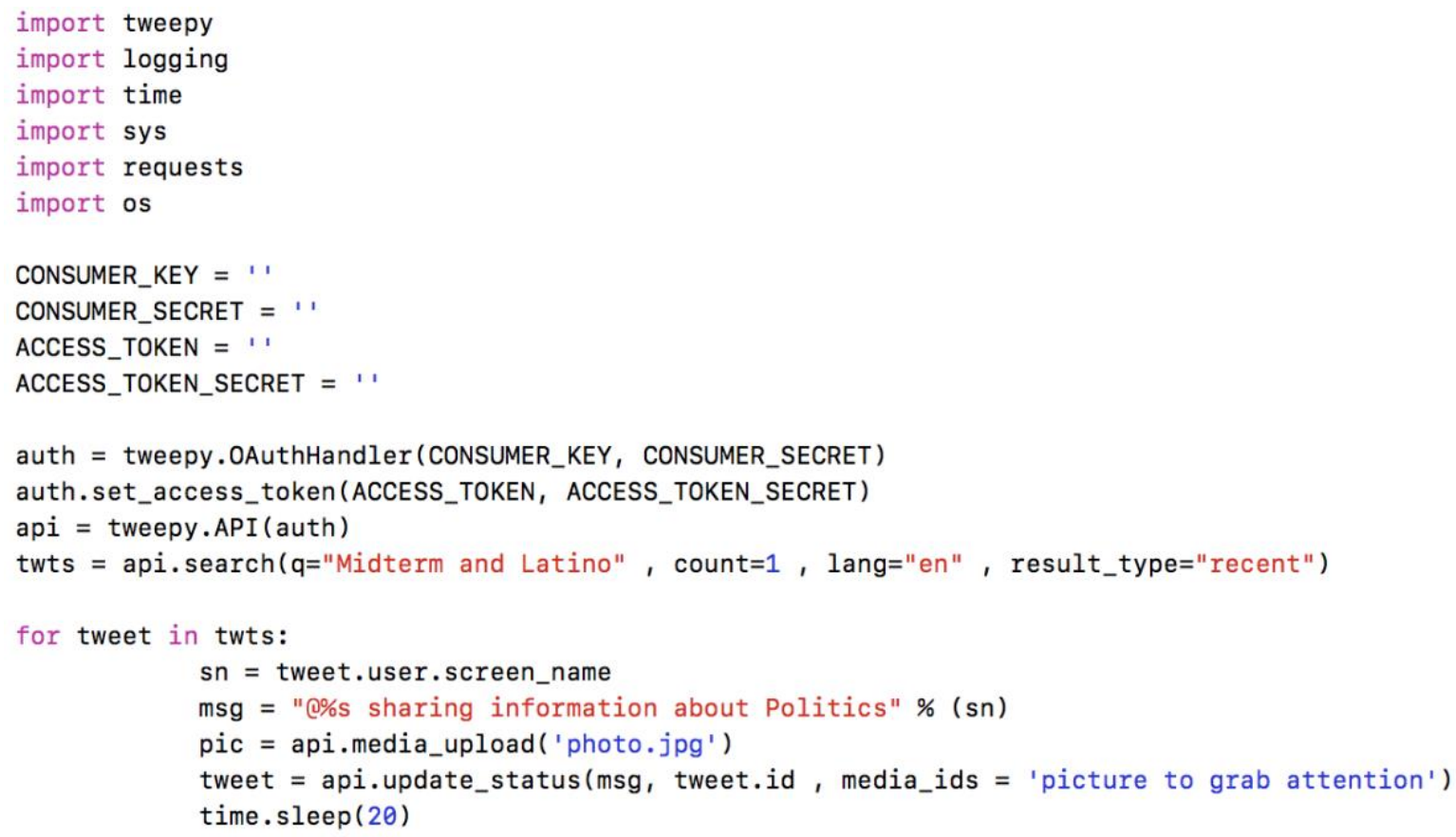

Figure 5.2: A python script to run twitter bot and share information 


\section{Chapter 6}

\section{Discussion}

Current research has focused on how political disinformation targets populations at large. However, there is a lack knowledge of how disinformation is targeting minorities, especially Latinos. This research starts to address this gap by investigating how Latinos politicians engage with crowd and how Latinos are targeted (mentioned, discussed) on Reddit and Twitter during the 2018 midterm elections. Through the analysis, it was identified that Latinos appeared to have been targeted differently on each social media platform.

On Twitter the main actors targeting Latinos were NGOs. However, these NGOs did not appear to target all Latinos, but rather focused primary on those who had been in the US for decades. The vast majority of their content was about DACA or voting registration (both policies related to Latinos who had been in the US since they were either kids or who had been long enough in the US to become citizens). These organizations seemed to rarely cover issues pertaining to other types of Latinos. This was especially noticeable when comparing their activity on Twitter to the people on Reddit.

On Reddit, spikes were seen in the number of posts early on in the year when people started mentioning and covering the situation of Latino families who had just arrived in the US and were being separated at the border. While the NGOs also briefly discussed these topics on Twitter, they did not give them the same visibility as the topics that were concerned with long-term Latinos in the US. It is important to note that the Latino community in the US is 
typically divided into subgroups like Mexicans, Puerto Ricans, Cubans, and these subgroups do not tend to socialize with each other [42]. This might be implicitly leading the NGOs to unintentionally also create subdivisions between Latinos in the US (Latinos who are new and Latinos who have been in the US for a longer time.) As a consequence, people following these NGOs (who in the media are presented as the main organizations targeting Latinos during the midterms) might obtain an incomplete picture of what is currently happening in the political ecosystem. This could also push a further division in Latinos (as in a way, the NGOs with their social media content are creating a narrative of separating "new and old Latinos").

It might also be alarming to consider that the groups that did target and covered more generally all Latino-related topics, were primarily political trolls (i.e., users on the subreddit r/The_Donald). Political trolls also had a number of dynamics to turn conversations around Latinos into something interesting and engaging for everyone. For instance, vast evidence of how political trolls introduced mega-threads to drive a large number of people to discuss topics around Latinos and the midterm elections. The study found evidence that these megathreads were happening at least once per week in the political troll subreddit. Through these mega-threads people on Reddit appeared to contextualize, explain, and discuss in detail the political ecosystem, especially related to all Latino groups. This type of social interaction where people take the time to explain in detail to others what is happening politically is something that our research had identified is effective for engaging and mobilizing individuals to action [10]. The study also uncovered that political trolls created several AMA's (Ask Me Anything sessions) on Reddit with congressional candidates and political personalities where they discussed political topics regarding Latinos and the midterm elections. This type of dynamics might also help to turn the topic of Latinos and politics into 
something interesting and through which they can more effectively mobilize people to the polls.

People on Reddit also actively shared photos of Latinos supporting particular political candidates, especially Pro-Trump candidates. On Twitter, such behaviors were observed from celebrities who also supported particular Republican candidates and appeared to push Trump's agenda among the Latino community. By having a right celebrity endorsement, a political party can gain a larger number of votes [43]. Opera Winfrey's support to Obama increased vote contribution for Obama by about 1 million additional votes [44].

It can be seen that NGOs were very persistent when it comes to using emotional words in their tweets. As emotions come to play when making important decisions [34], how someone shares their information and affects someone take on a specific topic through emotional information sharing becomes very important to study, especially for a topic like politics. With such persistent use of emotional words, NGOs could emotionally reach out Latino community with an intent to politically mobilize them.

During the midterm elections, it becomes extremely important to understand how minorities are being targeted on social media. With this research, it can be observed that political trolls overall appear to have much more sophisticated techniques for targeting Latinos and creating engaging content. The NGOs on Twitter appeared to suffer from their own social partition that leads them to not cover all political events regarding Latinos. Also, the study shows that NGOs appear to have fewer strategies for engaging their audiences. 


\section{Chapter 7}

\section{Conclusion, Limitation and Future Works}

Famous people with pro-Trump sentiment and NGOs supporting long term Latino immigrants have been targeting Latino on Twitter and trolls on Reddit have been successfully targeted and engaged Latinos on Reddit. Apart from that, political NGO's who were supposed to explain political ecosystem to Latinos in the US focus very less on politics.

The insights this investigation provides are limited by the methodology and population we studied. Our investigation also focused on breath, rather than on depth. As a result, we do not know much about the identities of the people participating in Twitter, Reddit or the organizations and their concern regarding disinformation targeted toward the Latino community in the US. The Twitter API has restricted the amount of data that can be retrieved from Twitter and is designed in a such a way so as not to give all the tweets related to keywords we were looking for. Involving third parties that provides all those tweets upon certain price could give better insights about the topic and authors that are targeting the Latino community.

Future research could involve conducting detailed interviews with actors of different organizations who have some relationship to the use of social media and/or a history of engagement in online politics and digital social life. It would also be good to study how the authors that were able to generate interaction for midterm have impacted Latino community. 
Future work could also investigate how these interactions on social media affect people's voting behavior.

\section{Bibliography}

[1] Madden, M., \& Zickuhr, K. (2011). 65\% of online adults use social networking sites. Pew Internet \& American Life Project, 1-14.

[2] Purcell, K., Rainie, L., \& Brenner, J. (2012). Search engine use 2012.

[3] Khang, H., Ki, E. J., \& Ye, L. (2012). Social media research in advertising, communication, marketing, and public relations, 1997-2010. Journalism \& Mass Communication Quarterly, 89(2), 279-298.

[4] Tucker, J., Guess, A., Barberá, P., Vaccari, C., Siegel, A., Sanovich, S., ... \& Nyhan, B. (2018). Social Media, Political Polarization, and Political Disinformation: A Review of the Scientific Literature.

[5] Persily, N. (2017). The 2016 US Election: Can democracy survive the internet? Journal of democracy, 28(2), 63-76.

[6] Wooley, S., \& Howard, P. (2016). Political communication, computational propaganda, and autonomous agents: Introduction. International Journal of Communication, 10, 4882-4890.

[7] Woolley, S. C., \& Howard, P. N. (2017). Computational propaganda worldwide: Executive summary. Computational Propaganda Project.

[8] Krogstad, J. M., Lopez, M. H., López, G., Passel, J. S., \& Patten, E. (2016). Millennials make up almost half of Latino eligible voters in 2016. Pew Research Center, January 19.

[9] Flores, A., \& Lopez, M. H. (2018). Key facts about Latinos in the 2018 midterm elections. Pew Research Center, October 15.

[10] Flores-Saviaga, K. B. S. S., C. (2018). Mobilizing the trump train: Understanding collective action in a political trolling community. International 12th AAAI Conference on Web and Social Media, ICWSM '18.

[11] Woolley, S. (2018, July 26). It's Time to Examine How Online Disinformation Affects Social Groups [Blog post]. Retrieved from https://lasvegas.adl.org/its-timeto-examine-how-online-disinformation-affects-social-groups/

[12] Nine first-time Latino candidates are running for congressional seats (2014, October 29), Fox News. Retrieved from https://www.foxnews.com/politics/nine-first-timelatino-candidates-are-running-for-congressional-seats

[13] "49 CFR Part 26". Retrieved 2012-10-22. 'Hispanic Americans,' which includes European-descended persons of Mexican-, Puerto Rican-, Jamaican-, Cuban, Dominican-, Central or South American

[14] "US Small Business Administration 8(a) Program Standard Operating Procedure" (PDF). Archived from the original (PDF) on 2006-09-25. Retrieved 2012-10-22. SBA has defined 'Hispanic American' as an individual whose ancestry and culture 
are rooted in South America, Central America, Cuba, Puerto Rico, the Dominican Republic, Mexico, or the Iberian Peninsula, including Spain and Portugal.

[15] "Demand for Democracy". The Pew Center on the States. Archived from the original on 2010-06-18. Retrieved 2011-10-13.

[16] Desilver, D. (2014). Voter turnout always drops off for midterm elections, but why. Facttank-News in the Numbers, Pew Research Center. Accessed on Sep, 9, 2018.

[17] "Hispanic voters and the 2018 midterm elections." Pew Research Center, Washington, D.C. (2018) Retrieved from http://www.pewhispanic.org/2018/10/25/hispanic-voters-and-the-2018-midtermelections

[18] Shultz, R. H., \& Godson, R. (1984). Dezinformatsia: Active measures in Soviet strategy. Potomac Books.

[19] Antoniadis, S., Litou, I., \& Kalogeraki, V. (2015, October). A model for identifying misinformation in online social networks. In OTM Confederated International Conferences" On the Move to Meaningful Internet Systems" (pp. 473-482). Springer, Cham.

[20] Clement, S., Borchers, C. (2018, January 24). Facebook plans to crowdsource media credibility. This chart shows why that will be so difficult. The Washington Post. Retrieved from www.washingtonpost.com/news/the-fix/wp/2018/01/24/facebookplans-to-crowdsource-media-credibility-this-chart-shows-why-that-will-be-sodifficult/

[21] Perisic, K. (2018, July 13). Here's how many Twitter followers influential politicians lost. The Daily Caller. Retrieved from www.dailycaller.com/2018/07/13/twitter-followers-influential-politicians/

[22] Disparte, D. (2018, July 10). Why we should care about Twitter's Purge of 70 million accounts. Forbes. Retrieved from www.forbes.com/sites/dantedisparte/2018/07/10/why-we-should-care-abouttwitters-purge-of-70-million-accounts/\#525066252355

[23] Hernon, P. (1995). Disinformation and misinformation through the Internet: Findings of an exploratory study. Government Information Quarterly, 12(2), 133139.

[24] Allcott, H., \& Gentzkow, M. (2017). Social media and fake news in the 2016 election. Journal of Economic Perspectives, 31(2), 211-36.

[25] Kadlec C (2011) The goal is power: The global warming conspiracy. Forbes. Retrieved from www.forbes.com/sites/charleskadlec/2011/07/25/the-goal-ispo.werthe-global-warming-conspiracy/

[26] Weeks, B. E. (2015). Emotions, partisanship, and misperceptions: How anger and anxiety moderate the effect of partisan bias on susceptibility to political misinformation. Journal of Communication, 65(4), 699-719.

[27] Barreto, M. A., Manzano, S., Ramirez, R., \& Rim, K. (2009). Mobilization, participation, and solidaridad: Latino participation in the 2006 immigration protest rallies. Urban Affairs Review, 44(5), 736-764.

[28] Michelson, M. R. (2003). Getting out the Latino vote: How door-to-door canvassing influences voter turnout in rural central California. Political Behavior, 25(3), 247263.

[29] Panagopoulos, C., \& Green, D. P. (2011). Spanish-language radio advertisements and Latino voter turnout in the 2006 congressional elections: Field experimental evidence. Political Research Quarterly, 64(3), 588-599.

[30] Fogg, B. J. (2009, April). A behavior model for persuasive design. Proceedings of the 4th international Conference on Persuasive Technology (p. 40). ACM. 
[31] Del Vicario, M., Bessi, A., Zollo, F., Petroni, F., Scala, A., Caldarelli, G., ... \& Quattrociocchi, W. (2016). The spreading of misinformation online. Proceedings of the National Academy of Sciences, 113(3), 554-559.

[32] Gutierrez, C. (2018) Hispanics Love Social Media-Especially Video. Retrieved from https://www.pm360online.com/hispanics-love-social-media-especially-video/

[33] Lopez, M. H., Gonzalez-Barrera, A., \& Patten, E. (2013). Closing the digital divide: Latinos and technology adoption.

[34] "Snapshot: The Day After Election Day," Facebook, accessed Oct. 15, 2011, http://www.facebook.com/notes/uspolitics-on-facebook/snapshot-the-day-afterelection-day/448930025881.

[35] Barreto, M. A. (2007). The Role of Latino Candidates in Mobilizing Latino Voters: Revisiting Latino Vote Choice. Latino politics: identity, mobilization, and representation, 63-89.

[36] Jason Wilson, 2011. "Playing with politics: Political fans and Twitter faking in postbroadcast democracy," Convergence, volume 17, number 4, pp. 445-461.

[37] Gerber, A. S., Green, D. P., \& Shachar, R. (2003). Voting may be habit-forming: evidence from a randomized field experiment. American Journal of Political Science, 47(3), 540-550.

[38] Cobb. K. (2017). People are cancelling their subscriptions to boycott Netflix's 'dear white people'. Decider. Retrieved from https://decider.com/2017/02/09/dear-whitepeople-triggers-netflix-boycott/.

[39] Crum, M. (2016). Pro trump trolls target Megyn Kelly's new book on amazon. Huffington Post. Retrieved from https://www.huffingtonpost.com/entry/pro-trumptrolls-target-megyn-kellys-new-book-on-amazon_us_58333eb4e4b099512f840828.

[40] Hasan, M. (2018). How the right-wing fox news became donald trump's state propaganda channel. Retrieved from https://www.newstatesman.com/world/northamerica/2018/05/how-right-wing-fox-news-became-donald-trump-s-statepropaganda-channel.

[41] Howard, P. N., Savage, S., Saviaga, C. F., Toxtli, C., \& Monroy-Hernández, A. (2016). Social media, civic engagement, and the slacktivism hypothesis: Lessons from Mexico's “El Bronco". Journal of International Affairs, 70(1), 55-73.

[42] Stokes, A. K. (2003). Latino group consciousness and political participation. american politics research. American Politics Research, 31(4), 361-378.

[43] Veer, B. I. M. B. A., Ekant. (2010). If Kate voted conservative, would you?: The role of celebrity endorsements in political party advertising. European Journal of Marketing, 44, 436-450.

[44] Zubcevic-Basic, N. (2016). Us election: what impact do celebrity endorsements really have?-the conversation. The Converstation. Retrieved from https://theconversation.com/us-election-what-impact-do-celebrity-endorsementsreally-have- 66204.

[45] Edelman, A. (2017). Trump ends daca program, no new applications accepted. NBC News. Retrieved from https://www.nbcnews.com/politics/immigration/trumpdreamers-daca-immigration-announcement- n798686.

[46] News, B. (2018). In violation of texas law, most high schools aren't giving students the chance to register to vote. Retrieved from http://www.blacknewsportal.com/inviolation-of-texas-law-most-high-schools-arent-giving-students-the-chance-toregister-to-vote.

[47] Leighley, J. E. (2001). Strength in numbers?: The political mobilization of racial and ethnic minorities. Princeton University Press. 
[48] Gambino, L. (2018, November 14). The guardian. Retrieved from https://www.theguardian.com/us-news/2018/nov/14/latino-turnout-up-174-in-2018midterms-elections-democrats-say 